\title{
Novel immunological and genetic factors associated with vitiligo: A review
}

\author{
SALVADOR LUIS SAID-FERNANDEZ ${ }^{1}$, CELIA NOHEMI SANCHEZ-DOMÍNGUEZ ${ }^{1}$, \\ MAURICIO ANDRES SALINAS-SANTANDER ${ }^{2}$, HERMINIA GUADALUPE MARTINEZ-RODRIGUEZ ${ }^{1}$, \\ DAVID EMMANUEL KUBELIS-LOPEZ ${ }^{3}$, NATALIA ARANZA ZAPATA-SALAZAR ${ }^{3}$, \\ OSVALDO TOMAS VAZQUEZ-MARTINEZ ${ }^{3}$, UWE WOLLINA ${ }^{4}$, TORELLO LOTTI ${ }^{5}$ and \\ JORGE OCAMPO-CANDIANI ${ }^{3}$
}

\author{
${ }^{1}$ Department of Biochemistry and Molecular Medicine, Jose Eleuterio Gonzalez Medicine School and University Hospital, \\ Autonomous University of Nuevo León, Monterrey, Nuevo León 64460; ${ }^{2}$ Research Department, \\ Autonomous University of Coahuila, Faculty of Medicine Saltillo Unit, Saltillo, Coahuila 25000; \\ ${ }^{3}$ Dermatology Service, Jose Eleuterio Gonzalez Medicine School and University Hospital, \\ Autonomous University of Nuevo León, Monterrey, Nuevo León 64460, Mexico; \\ ${ }^{4}$ Department of Dermatology and Allergology, Skin Cancer Center, Städtisches Klinikum, \\ D-01067 Dresden, Germany; ${ }^{5}$ Department of Dermatology and Venereology, \\ University Guglielmo Marconi of Rome, I-00193 Rome, Italy
}

Received May 30, 2020; Accepted September 15, 2020

DOI: $10.3892 /$ etm.2021.9743

\begin{abstract}
Vitiligo is a skin disorder characterized by depigmentation of the skin due to a lack of melanin. This condition affects men and woman of all ages and its incidence is not restricted by ethnicity or region. Vitiligo is a multifactorial disease, in which melanocytes, which serve important functions in skin pigmentation and immune processes, are impaired. There is sufficient evidence that immunological and genetic factors are primarily responsible for the destruction and dysfunction of melanocytes. Therefore, genetic DNA sequence variants that participate in skin homeostasis, pigmentation and immune response regulation, as well as altered expression patterns, may contribute to the risk of developing vitiligo. The current review presented an overview of the mechanism of pigmentation and of currently known factors involved in depigmentation, as well as the classification, epidemiology, associated comorbidities, risk factors, immunopathogenesis and several genetic and molecular changes associated with vitiligo.
\end{abstract}

Correspondence to: Dr Jorge Ocampo-Candiani, Dermatology Service, Jose Eleuterio Gonzalez Medicine School and University Hospital, Autonomous University of Nuevo León, Av. Madero y Gonzalitos s/n, Colonia Mitras Centro, Monterrey, Nuevo León 64460, Mexico

E-mail: jocampo2000@yahoo.com.mx

Key words: epidemiology, pathogenesis, immunology, genetics, vitiligo

\section{Contents}

1. Overview

2. Immunopathogenesis of vitiligo

3. Genetic factors associated with vitiligo

4. Conclusions

\section{Overview}

Vitiligo is a multifactorial disease characterized by a deficiency or absence of skin pigmentation due to the loss or inactivity of melanocytes in the basal layer of the epidermis, mucosa or other organs $(1,2)$. The pathogenesis of this disease involves a convergence of genetic, environmental and metabolic factors, as well as autoimmune responses (3). The clinical hallmark of vitiligo is the lack of melanin and the initial manifestation of vitiligo can appear as the premature whitening or graying of hair $(1,4)$. In the skin, vitiligo manifests as hypochromic or achromic macules and patches, which increase in number and size over time (4). These depigmented macules and patches may occur anywhere on the body. However, they are observed more frequently around the orifices, genitals and sun-exposed areas (5). The understanding of how and why vitiligo lesions are formed and extended is crucial. To understand these complex processes, it is necessary to understand how the normal pigmentation mechanism functions and contributes to the organism's homeostasis.

Melanocytes. Melanocytes are located in the stratum basale (basal layer) of the epidermis, where they interact through dendrites with keratinocytes (6). These cells have two functions: i) the production of melanin; and ii) a role in the immune 
system (7). The number of melanocytes is relatively constant, with between 500 and 2,000 melanocytes $/ \mathrm{mm}^{2}$ in the skin. Melanocytes constitute $\sim 5-10 \%$ of the cells located in the basal layer of the epidermis (8).

Melanins, a group of natural pigments produced by melanocytes, are derived from tyrosine and directly from dihydroxyphenylalanine (DOPA) (9). DOPA is the product of the enzyme tyrosinase (diphenol oxidase), a copper enzyme that utilizes molecular $\mathrm{O}_{2}$ to metabolize DOPA from tyrosine. Exposure to UV light activates tyrosinase in melanosomes; this is the initial step of melanin synthesis (10) that occurs in melanocytes (11). DOPA is converted to DOPA quinone and several intermediates are formed until indolequinone is produced and polymerized to form melanin (12). Eumelanin (brown or black in color) is the most common product in humans. However, in the presence of cysteine, eumelanin is converted to pheomelanin (red or yellow in color) $(9,12,13)$. A combination, mainly of melanin and carotene, produces color in the skin, eyes and hair (13). Melanin can absorb broadband UV light and protects skin cells from UVB radiation $\left(\mathrm{UVB}_{\mathrm{R}}\right)$ damage, thereby decreasing the risk of carcinogenesis. Additionally, melanin has antioxidant and radical scavenging properties (14).

Following synthesis in melanocytes, melanin is stored in organelles termed melanosomes, which are transported to nearby keratinocytes to induce pigmentation (15). Additionally, melanocytes serve a role in the immune system and express various immune molecules, such as toll-like receptors and proinflammatory cytokines and chemokines (15). The major histocompatibility complex (MHC) class II is located only on professional antigen presenting cells (APCs), including melanocytes, dendritic cells, macrophages and B cells, as opposed to the widely distributed MHC class I located on the majority of vertebrate cells (16). Cytokine-stimulated melanocytes express surface proteins, including CD40, a costimulatory protein expressed and required by APCs, and intercellular adhesion molecule 1 (ICAM1) (15), an endothelial and leukocyte-associated transmembrane protein. ICAM1 facilitates leukocyte-endothelial transmigration and increases the risk of melanoma metastasis (17). Additionally, melanocytes express numerous proinflammatory cytokines, including IL-1, -3, -6 and -8 , TNF- $\alpha$ and TGF- $\beta(18,19)$. Furthermore, melanocytes secrete cytokines following activation by pattern recognition receptors, which recognize microbe-associated molecular patterns (MAMPs). MAMPs can be proteins, carbohydrates or lipids from pathogenic microorganism that are exposed to immune cells (18). Melanocytes can also be activated by cytokines secreted by other nearby immune cells (18).

UVA is mainly responsible for indirect DNA damage by the generation of reactive oxygen species (ROS) (20). ROS produce single-strand breaks in DNA and crosslinks in DNA proteins $(21,22)$. DNA absorbs $U_{V} B_{R}$ at wavelengths of 245-290 $\mathrm{nm}$ (23). Therefore, $U_{\mathrm{VB}}$ is a powerful mutagen (24). The predominant DNA lesions formed are cyclobutane pyrimidine dimers (CPDs) and 6-4 pyrimidine-pyrimidones (6-4PPs). CPDs and 6-4PPs are the most important UVB-induced photoproducts with potential mutagenic properties, since they can cause highly specific mutations, such as CC to TT double base substitutions and C to $\mathrm{T}$ substitutions in dipyrimidines (25).
The following sections describe the different types of vitiligo and which factors intervene in their initiation and development.

Classification of vitiligo. According to the revised classification of vitiligo by the Vitiligo Global Issues Consensus Conference (VGICC) published in 2012 (26), there are three recognized clinical forms of vitiligo: i) non-segmental; ii) segmental; and iii) unclassified. Each of these categories have further subclassifications, as described below.

Non-segmental vitiligo. This term is recommended for all non-segmental forms of vitiligo with the following subclassifications: i) generalized vitiligo, formerly termed vitiligo vulgaris, is frequently bilateral and presents with symmetric macules and patches, affecting any part of the body; however, most commonly the hands, face and fingers are affected; ii) acrofacial vitiligo, which is limited to the face, head, hands and feet; 'lip-tip' is considered a subcategory, only affecting the cutaneous lips and fingertips; iii) vitiligo universalis, which affects $80-90 \%$ of the body surface; iv) mucosal vitiligo, which is the depigmentation of the oral and genital mucosae; v) mixed vitiligo, which refers to the simultaneous presentation of segmental and non-segmental vitiligo; and vi) the rare variants, including minor vitiligo, follicular vitiligo and vitiligo punctate.

Segmental vitiligo. This subclassification presents unilaterally as an asymmetric distribution of macules and patches, generally around the midline. Segmental vitiligo can be monosegmental, bisegmental or plurisegmental.

Unclassified vitiligo. This term is used for lesions that do not evolve into segmental or non-segmental vitiligo after presenting for 1-2 years and includes the following variants: i) focal vitiligo, referring to small patches of skin or mucosal depigmentation; and ii) single mucosal site involvement, which only affects oral or genital mucosa.

Koebner phenomenon. The Koebner phenomenon, also known as the isomorphic response, refers to the development of vitiligo lesions following trauma. These lesions appear on a site previously unaffected by vitiligo (27). The Koebner phenomenon is divided into the following subtypes: i) type 1, depigmented areas following trauma or injury in the past year; ii) type $2 \mathrm{~A}$, depigmented lesions in areas of repeated pressure or friction; iii) type $2 \mathrm{~B}$, linear, punctiform or crenate depigmented lesions in areas of repeated pressure or friction; and iv) type 3, experimentally induced lesions due to trauma, which can be further subdivided into superficial irritation (level 1), superficial epidermal trauma (level 2) and dermoepidermal trauma (level 3) (27).

Further classification of vitiligo: Stable and active vitiligo. The classification of stable or active vitiligo is beneficial for dermatologists to specialize treatment strategies for patients. This classification accounts for the evolution of skin lesions. Vitiligo is considered active when there is growth of previous lesions, the appearance of new lesions and/or the presence of confetti-like depigmentation or trichrome lesions $(4,26,28)$. 


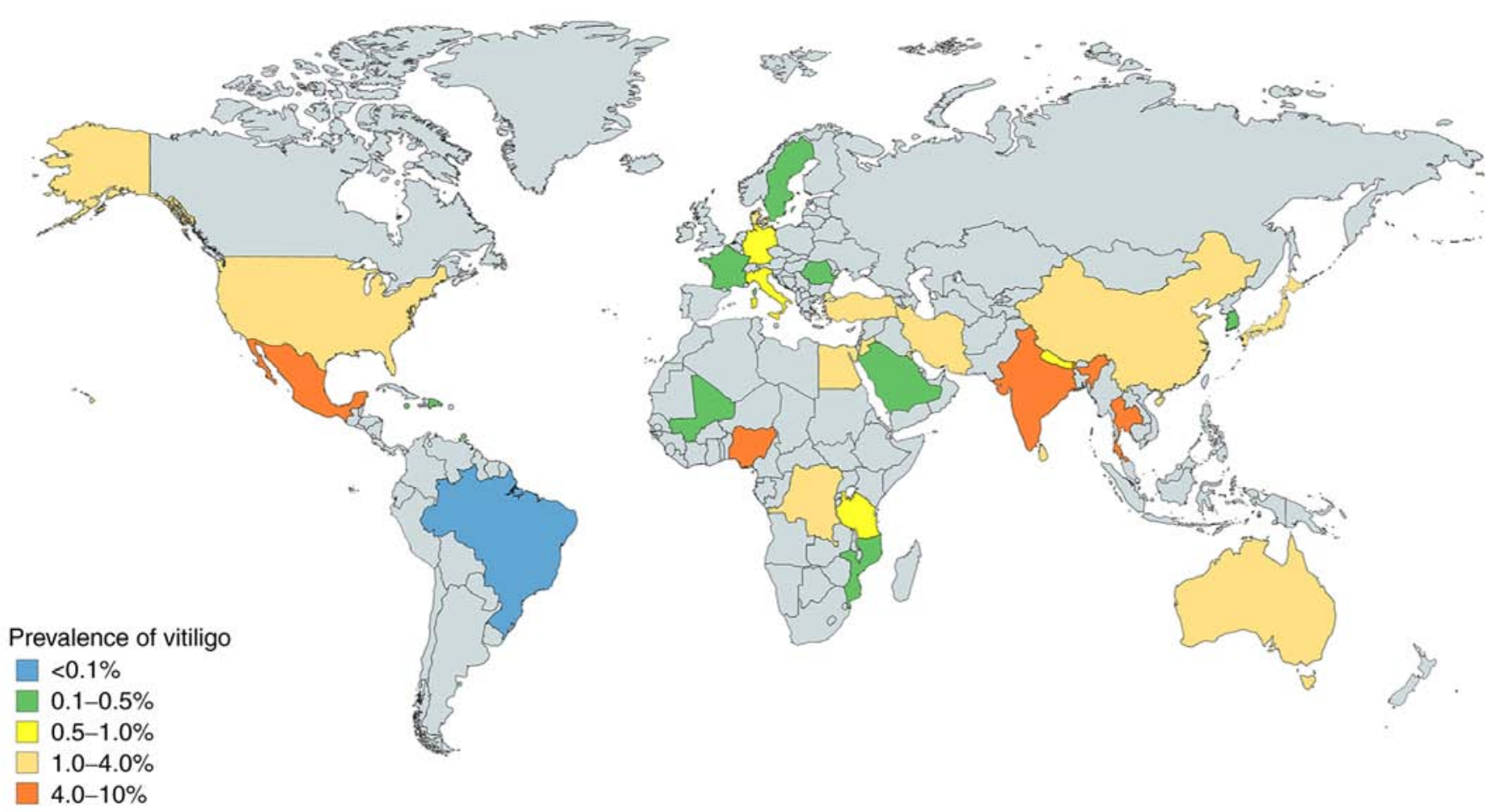

Figure 1. Worldwide prevalence of vitiligo. Estimated prevalence rates at all ages obtained from studies conducted globally. The grey area denotes regions with unavailable vitiligo data $(31,32,34,35)$.

The time frame used as a cut-off for vitiligo stability or activity varies according to different authors, ranging from 6 weeks (29) to 2 years (30). The VGICC endorses a period of 1 year (26).

Epidemiology. Vitiligo is the most common depigmenting disorder, with a global prevalence of $\sim 0.06-8.8 \%$, according to data published between 1964 and 2017 (31-35). Vitiligo affects men and women equally (33). However, there are differences in the prevalence of vitiligo according to geographical regions. The countries with the highest reported prevalence are India (8.8\%), Mexico (2.6-4\%) and Japan ( $\geq 1.68 \%$; Fig. 1) $(31,32,34,35)$.

Vitiligo affects young and old individuals. The median age of presentation was 37.6 years in China (range, 5-79 years) (36), while the mean age of vitiligo presentation was 27.02 years in Pakistan (range, 5.5 months to 82 years) (37) and 26.4 years in Mexico (range, 7 months to 74 years) (38). However, the highest incidence of vitiligo has been observed in childhood or young adulthood, peaking at 10-30 years (39).

Comorbidities. The role of autoimmunity in vitiligo is due to the high prevalence of auto-antibodies against melanocytes and by the simultaneous presence of other autoimmune diseases, including Hashimoto's thyroiditis, diabetes mellitus, Addison's disease, alopecia areata and/or ophthalmic anomalies, such as iritis (40-42). These associations vary according to age and sex. For example, Grave's disease, Hashimoto's thyroiditis, atopic dermatitis, rheumatoid arthritis, systemic lupus erythematosus and Sjögren's syndrome have been reported to be associated with vitiligo in women, while psoriasis with men (43) and myasthenia gravis with young patients $(<40$ years old) (44).
Worldwide, thyroid dysfunction in patients with vitiligo ranges between 0 and 52\%, according to data published up to 2012 (45). Sedighe et al (46) reported the presence of thyroid disorders in $17.4 \%$ of patients with vitiligo and the most common presentation was hypothyroidism in Iran. In India, Gopal et al (47) reported hypothyroidism in $30 \%$ of patients with vitiligo. In 2014, our previous study reported that hyperthyroidism, hypertension, atopy, diabetes mellitus and alopecia areata were associated with vitiligo and that the disorder with the highest frequency was hyperthyroidism in Mexico (22\%) (38). All of the aforementioned disorders appear to be associated with autoimmunity and genetic factors.

Increased levels of anti-melanocyte and antinuclear antibodies and complement component 4 have been described in a recent study in Egyptian patients with vitiligo. These increased levels had a positive correlation with disease severity (48). Studies on the number of auto-antibodies in different ethnic groups of patients with vitiligo are limited. A meta-analysis of 25 case-controlled studies reported that anti-thyroperoxidase (ATPO), anti-thyroglobulin (ATG), antinuclear, anti-gastric parietal cell (AGPCA) and anti-adrenal antibodies were significantly higher in patients with vitiligo compared with the control group (49). Therefore, it is necessary to consider the characteristics of diseases, including autoimmune thyroid disease for ATPO and ATG auto-antibodies, pernicious anemia and gastric atrophy for AGPCA, in patients with vitiligo (49).

Vitiligo can affect several members of the same family, indicating a genetic risk. Among patients with vitiligo, $\sim 1 / 5$ th of patients have at least one affected close relative (50). It has been reported that patients with a family history of vitiligo are at a higher risk of developing this disease at an early age compared with those without a family history of vitiligo (38). 
Furthermore, Alenizi (51) revealed that consanguinity is associated with an increased incidence of vitiligo (51). Nevertheless, the inheritance pattern of vitiligo is complex as multiple causative factors are involved (50).

The association of vitiligo with autoimmune responses is further supported by the presence of lymphocytes in the dermis of early lesions and auto-antibodies against melanocytes in numerous patients with active vitiligo $(39,44)$. Furthermore, the positive response from patients with vitiligo to treatments with immunomodulatory agents, including corticosteroids and phototherapy, confirms that a key aspect of vitiligo includes an autoimmune reaction against factors involved in the pigmentation of tissues and organs (52).

Risk factors. Certain internal or external factors may be involved with the ability of melanocytes and keratinocytes to resist harmful effects.

Internal factors. Two of the most important internal factors, activation of the immune system and heritability, have been discussed above. Notably, another internal risk factor for vitiligo is cancer. Franks and Slansky (53) demonstrated the risk of cancer development in patients with autoimmune and chronic inflammatory diseases. Furthermore, Asilian et al (54) reported a 73-year-old patient with new onset vitiligo who developed esophageal cancer several years after the diagnosis of vitiligo. Additionally, Balasubramanian (55) reported two cases of vitiligo associated with breast cancer. However, whether vitiligo was a consequence of cancer or whether both cancer and vitiligo developed in these patients due to genetic disorders remains unknown. Genetic factors associated with vitiligo will be described in subsequent sections.

External factors. Multiple external factors, including sunburns, physical trauma, agricultural and industrial pollution, and emotional stress, have been reported to induce vitiligo; consequently, a number of these factors are considered as environmental risk factors of vitiligo $(56,57)$. However, sometimes establishing causality and not only association is difficult, and must be evaluated under the basis of scientific rigor this.

\section{Immunopathogenesis of vitiligo}

The immune hypothesis is supported by several factors, including the association with autoimmune conditions, organ-specific antibodies, antibodies against antigens in melanocytes and the participation of immune cells.

Auto-antibodies and antigens. Several melanocyte antibodies are associated with disease extension. IgG and complement component 3 (C3) deposits have been observed in the basal membrane zone of skin lesions $(58,59)$. C 3 serves a key role in the complement system and contributes to innate immunity $(58,59)$.

Additionally, numerous specific autoantigens associated with pathogenesis have been observed in patients with vitiligo, including tyrosinase, tyrosinase-related protein, Melan-A/melanoma antigen recognized by T cells 1 (MART1), melanosomal matrix glycoprotein (gp100), SOX10 and melanin-concentrating hormone receptor $1(60)$.
Cytokines. Multiple studies have investigated the role of cytokines in vitiligo. IL-6 facilitates leukocyte-melanocyte interactions and IL-8 attracts neutrophils (60). Additionally, IL-17 has been associated with vitiligo (61). T helper 17 (Th17) cells are a subset of pro-inflammatory $\mathrm{T}$ helper cells that infiltrate the upper dermis in active vitiligo (62) and are potent producers of IL-17 and IL-17F. IL-17 synergizes with local inflammatory mediators, including IL-1 $\beta$, IL- 6 and TNF- $\alpha$, and inhibits melanocyte proliferation (63). Furthermore, IL-17 expression is upregulated in multiple autoimmune inflammatory diseases, such as rheumatoid arthritis, systemic lupus erythematosus, psoriasis and atopic dermatitis (62). The levels of IL-17 in serum have been associated with the extent and duration of depigmentation and IL-17 concentration is increased in perilesional skin compared with in depigmented skin $(62,63)$. IL-17 and TNF- $\alpha$ suppress melanogenesis by synergistically downregulating genes of the pigmentation pathway, causing hypopigmentation disorders (64). Additionally, TNF- $\alpha$ contributes to keratinocyte apoptosis by decreasing the levels of melanogenic cytokines $(65,66)$. Elucidating these changes in cytokines has led to the use of methotrexate (MTX), a folate antagonist, in the treatment of vitiligo (67). A previous study has demonstrated that MTX decreases the number of T cells producing TNF- $\alpha$ (67). Furthermore, case reports and studies using oral MTX in vitiligo reported variable results, including arrested progression, marked skin repigmentation or no significant changes, and when MTX was compared with oral dexamethasone minipulse, both were considered equally effective (67-70). Recently, a topical formula of MTX was used in a case report with significant improvement in repigmentation of the vitiligo lesion (71). However, further studies are required.

Plasmacytoid dendritic cells are part of the cell-infiltrate in progressive vitiligo and produce human Myxovirus resistance protein 1, an interferon-induced dynamin-like GTPase, which is associated with the recruitment of $\mathrm{CD}^{+}$ chemokine receptor $3^{+}\left(\mathrm{CXCR}^{+}\right) \mathrm{T}$ cells $(72,73)$. Additionally, plasmacytoid dendritic cells produce IFN- $\alpha$, which leads to the production of CXC motif chemokines, including C-X-C motif chemokine ligand (CXCL) 9 (CXCL9) and CXCL10, and serves as an initial signal for the recruitment of effector $\mathrm{T}$ cells and the amplification of inflammation (73). Previous studies have reported increased levels of CXCL9 and CXCL10 in vitiligo $(73,74)$. Furthermore, CXCL10 recruits melanocyte-specific $\mathrm{CD} 8^{+} \mathrm{T}$ cells, which migrate to the epidermis due to the interaction of CXCL10 with CXCR3, which is expressed on $\mathrm{T}$ cells in the blood and skin $(74,75)$.

$T$ cells. Cellular immunity serves an important role in the pathogenesis of vitiligo and epidermal cells other from melanocytes can induce an immune response in vitiligo (73). For instance, keratinocytes exposed to high levels of ROS express CXCL16, which stimulates the migration and infiltration of $\mathrm{CXCR6}^{+} \mathrm{CD}^{+} \mathrm{T}$ cells (killer $\mathrm{T}$ cells) in the skin (76). These $\mathrm{CD}^{+} \mathrm{T}$ cells detect specific antigenic proteins derived from melanocytes that are involved in melanin synthesis, including melanoma antigen Melan-A/MART1, gp100, tyrosinase, tyrosinase related protein (TYRP) 1-(-a protein specifically produced by melanocytes) -and TYRP2, also known as dopachrome tautomerase $(77,78)$. 
Skin biopsies have revealed $\mathrm{CD}^{+}$and $\mathrm{CD} 4^{+} \mathrm{T}$-cell infiltration in the margins of active lesions, with an increased $\mathrm{CD}^{+}$ to $\mathrm{CD}^{+}$ratio (79). Additionally, increased T-cell migration to the skin due to the increased expression of CD25 and MHC II, and the secretion of IFN- $\gamma$ have been demonstrated (80), while increased T-cell number has been reported to be associated with worse disease extent (81). Furthermore, $\mathrm{CD}^{+} \mathrm{T}$ cells serve an important role in vitiligo due to their association with autoimmune diseases $(60,80)$.

IFN- $\gamma$-dependent cytokines rely on the JAK-STAT pathway for signalling in the pathogenesis of vitiligo, and CXCL10 in keratinocytes is an important mediator of depigmentation $(82,83)$. Tofacitinib, a promising drug that acts on the JAK-STAT signaling pathway, blocks IFN- $\gamma$ signaling and downstream CXCL10 expression, leading to repigmentation in vitiligo (84). The study by Craiglow et al (85) was the first to demonstrate this pathogenesis-based therapy with tofacitinib.

Stressed melanocytes. Melanocytes have poor adaptability to stressors (73), including high levels of ROS, which causes an imbalance in the pro-oxidant and antioxidant levels (86). This increased oxidative stress damages melanocytes, leading to instability in the basal layer of the epidermis, lower catalase levels and elevated superoxide dismutase (SOD) in the blood of patients with vitiligo $(73,86)$. SOD participates in the degradation of the $\mathrm{O}^{-}$radical to $\mathrm{H}_{2} \mathrm{O}_{2}$ and $\mathrm{O}_{2}(86)$.

The accumulation of $\mathrm{H}_{2} \mathrm{O}_{2}$ inhibits catalase activity, which breaks down $\mathrm{H}_{2} \mathrm{O}_{2}$ to $\mathrm{H}_{2} \mathrm{O}$ and $\mathrm{O}_{2}$ (87). Catalase is downregulated by elevated ROS levels in vitiligo, leading to oxidative pathway imbalance and melanocyte destruction (88). Schallreuter et al (89) reported elevated $\mathrm{H}_{2} \mathrm{O}_{2}$ levels in patients with vitiligo compared with healthy controls. In addition to the oxidative imbalance, ROS may impede repigmentation by attenuating mitochondrial ATP production and impairing melanocyte destruction (90).

The use of antioxidants remains in study and has demonstrated variable results. Topic catalase for repigmentation in vitiligo reduces $\mathrm{H}_{2} \mathrm{O}_{2}$ and may prevent oxidative damage (91). Alshiyab et al (91) reported that the combination of topical pseudocatalase/dismutase gel and $0.1 \%$ tacrolimus ointment did not have markedly different results compared with $0.1 \%$ tacrolimus ointment monotherapy in children with $<10 \%$ of body surface area affected by vitiligo. However, clinical trials concerning antioxidants in the treatment of vitiligo are limited by the number of patients and studies with larger study populations are warranted.

The aforementioned information on the immunopathogenesis of vitiligo indicates that vitiligo may be initiated by metabolic stress due to ROS accumulation, particularly in the affected areas, suggesting that the use of antioxidants may have a potential therapeutic implication for the damaged oxidative pathways (92).

Boniface et al investigated melanocyte instability and observed that vitiligo melanocytes exhibited decreased expression of adhesion molecules, including E-cadherin, a central protein in cell-cell adhesion (73). Furthermore, Rezk et al (74) and Boniface et al (73) reported that stressed melanocytes secrete elevated levels of the chemokine $\mathrm{C}-\mathrm{C}$ motif ligand (CCL)-5, CXCL12 and IL-8. The chemokines CXCL12 and CCL5 are involved in T-cell recruitment, homing (the ability of lymphocytes to migrate) to the skin, and melanocyte-specific immunity $(73,74)$, while IL-8 is a potent chemotactic factor for neutrophils and amplifies the local inflammatory response. Additionally, melanocyte-derived CXCL12 and CCL5 support APCs, T-cell recruitment and T-cell activation in early vitiligo, confirming the role of these chemokines in the activation of melanocyte-specific immunity $(73,74)$.

Melanocytes and keratinocytes respond to aggressions by producing cytokines that attract and activate immune cells, mainly $\mathrm{CD}^{+} \mathrm{T}$ cells and $\mathrm{Th} 17$ cells, which recognize melanocyte surface proteins. Subsequently, $\mathrm{CD} 8^{+} \mathrm{T}$ cells and Th17 cells produce several cytokines, including TNF- $\alpha$, IFN- $\gamma$ and IL-17, which cause the most damage to melanocytes (73). Following this, local inflammation is established and amplified, and melanin production is inhibited, or, in poorer outcomes, apoptosis and loss of adherence are induced in melanocytes (73). Additionally, genetic factors serve a key role in vitiligo and a variety of these factors are closely associated with the immunologic process, as discussed in subsequent sections.

\section{Genetic factors associated with vitiligo}

Genes involved in the susceptibility of vitiligo. The participation of different loci of various genes has been described in families presenting with a high prevalence of vitiligo (93), including those located on chromosomes 4q13-q21, 1p31, $7 \mathrm{q} 22,8 \mathrm{p} 12$ and $17 \mathrm{p} 13$ (94). Table I presents several associations between genes associated with the susceptibility of vitiligo (95-100) and other autoimmune diseases, such as alopecia areata and Hashimoto thyroiditis (52).

Al-Shobaili (101) reported that the genetics of vitiligo include multiple susceptibility loci, genetic heterogeneity and incomplete penetrance with gene-gene and gene-environment interactions, and that the methods most commonly used for identifying genomic regions or candidate genes that mediate susceptibility to vitiligo include two approaches: i) genome-wide linkage analyses, which are performed by scanning the entire human genome for the identification of genomic regions associated with the development of vitiligo; and ii) association analyses of functional candidate genes with vitiligo onset by detecting specific candidate genes, which are expected to be associated with the condition considering their biological functions and performing association studies. Both of these approaches are based on the comparison of genetic information from healthy skin with vitiligo biopsies Association analyses of functional candidate genes better describe the genetic causes of vitiligo. A description of the genes identified to date are described in the following sections.

Vacuolar ion transporter 1 (VITI). Le Poole et al (102) reported that the $3^{\prime}$ portion of VIT1 is complementary to the $3^{\prime}$ end of MutS Homolog 6 mRNA, enabling the formation of RNA-RNA hybrids, which may interfere with G/T mismatch repair function.

Catalase (CAT). CAT encodes the four subunits of human CAT, which is bound to the heme group of the functional enzyme (103). Casp et al (104) published a case-control and 
Table I. Mutated genes associated with depigmentation mechanisms in vitiligo.

\begin{tabular}{llll}
\hline Database & Gene name & Protein & Function \\
\hline
\end{tabular}

$\begin{array}{ll}\text { Genetics Home Reference MITF } & \begin{array}{l}\text { Melanocyte inducing } \\ \text { transcription factor }\end{array}\end{array}$

Genetics Home Reference POMC Proopiomelanocortin

UniProtKB

DCT

UniProtKB

TYRP1

Dopachrometautomerase (dopachrome $\Delta$-isomerase, tyrosine-related protein 2)

Tyrosinase-related protein 1

Melanoma antigen

recognized by Th1 cells

UniProtKB

MLANA

Genetics Home Reference CAPN3 Calpain-3
Controls the development of melanin

and contributes to the color of hair, eyes and skin.

Following cleavage into peptides,

POMC serves different functions. The

peptides bind to melanocortin

receptors 1, 2, 3 and 4 (MC1R,

MC2R, MC3R and MC4R), triggering

signaling pathways and controlling

various important functions, such as

regulation of blood sugar levels,

protection of the body from stress and suppression of inflammation, regulation of pigment production, blood pressure, satiety, energy expenditure and weight loss.

Furthermore, three similar peptides, $\alpha$-, $\beta$ - and $\gamma$-(MSH), are derived from

POMC. The primary role of $\alpha-\mathrm{MSH}$ is melanocyte stimulation to produce and release melanin.

Converts dopachrome to DHICA,

which is an intermediate in the

biosynthesis of melanin.

Catalyzes the oxidation of

DHICA in the presence of bound $\mathrm{Cu}^{2+}$ ions.

Additionally, it may regulate or influence the type of melanin synthesized and, to a lesser extent, is capable of hydroxylating tyrosine and producing melanin.

Serves a vital role in the expression, stability, trafficking and processing of melanocyte premelanosome, which is critical for the formation of stage II melanosomes.

Located in the muscle cells in sarcomeres and its function is not well understood.

DHICA, 5,6-dihydroxyindole-2-carboxylic acid into indole-5,6-quinone-2-carboxylic acid; MSH, melanocyte-stimulating hormone.

family-based association study, which reported a decrease of CAT enzyme activity in patients with vitiligo. Furthermore, a concomitant accumulation of excess $\mathrm{H}_{2} \mathrm{O}_{2}$ was observed in the epidermis of the patients (104).

Furthermore, Mosaad et al (105) revealed that the T allele of the CAT $389 \mathrm{~T} / \mathrm{C}$ polymorphism may be a susceptibility risk factor for vitiligo in the Egyptian population. The results observed that TT genotype carriers of CAT 389 had the lowest levels of CAT, while the highest level of malondialdehyde was observed in AA genotype carriers of CAT, indicating that this polymorphism may be associated with increased oxidative stress in non-segmental patients with vitiligo (105).

Tenascin $C$ (TNC). TNC is an extracellular matrix protein implicated in the guidance of migrating neurons due to stimulation of angiogenesis in vitro (106). Le Poole et al (107) reported increased expression levels of TNC in vitiligo lesions. Furthermore, increased TNC has been demonstrated to be inversely correlated with the duration of the disease (107). TNC acts as an anti-adhesive molecule (108). Since fibroblasts 
secrete TNC, fibroblasts may malfunction in vitiligo (109) and, therefore, TNC upregulation may impair the adhesion of melanocytes to surrounding keratinocytes and facilitate the process of melanocytorrhagy (109).

Forkhead box D3 (FOXD3). This gene belongs to the forkhead family of transcription factors, which are characterized by a distinct forkhead domain (110). Mutations in this gene cause autoimmune susceptibility (111). FoxD3 has been indicated to coordinate a lineage switch between neural/glial and pigment phenotype in neural crest stem cells via melanocyte inducing transcription factor (MITF), a key regulator in melanin production and melanogenesis (111).

TNF- $\alpha$ (-308G/A) GA genotype. This genotype has been associated with the active form of generalized vitiligo (2). TNF- $\alpha$ serves an important role in vitiligo by destroying melanocytes through the induction of apoptosis via a caspase 3-dependent pathway (66). Additionally, TNF- $\alpha$ inhibits melanocyte stem cell differentiation (112). In the specific case of TNF- $\alpha$ (-308G/A), Wilson et al (113) reported a strong association between the TNF2 allele (-308A) and the human leukocyte antigen (HLA) A1, B8 and DR3 alleles, indicating that the haplotype may contribute to numerous autoimmune diseases, such as insulin-dependent diabetes mellitus, systemic lupus erythematosus, Graves' disease and celiac disease. Using a human B-cell line, a previous study used reporter genes under the control of two allelic TNF promoters to demonstrate that the TNF2 allele (-308A) was a stronger transcriptional activator compared with the TNF1 common allele (-308G) (114). Since patients with active vitiligo usually present with increased levels of several proinflammatory cytokines, including TNF- $\alpha$ (115), patients with vitiligo with the TNF2 allele produce higher levels of TNF- $\alpha$ and, consequently, have a higher risk of more severe and active depigmentation compared with patients who do not carry this allele (114).

Protein tyrosine phosphatase non-receptor type 22 (PTPN22) $(+1858 \mathrm{C} / \mathrm{T})$. Our previous study reported that patients who carry the heterozygous CT genotype have an increased risk of developing the active form of vitiligo (116). PTPN22 is a protein tyrosine phosphatase, non-receptor type 22 lymphoid (LYP). The PTPN22 single nucleotide polymorphism, rs2476601, results in an amino acid change from arginine to tryptophan at the 620 codon position. This variant, which is associated with increased vitiligo risk, prevents the interaction of LYP with the negative regulatory tyrosine kinase C-Src. As a result, the $\mathrm{T}$-cell receptor-associated kinases may be able to induce T-cell activation in an uncontrolled manner and increase the reactivity of the overall immune system, leading to a predisposition for autoimmune disorder susceptibility (116). Therefore, it has been hypothesized that individuals lacking the $\mathrm{C}$ allele of PTPN22 may have a decreased capacity to downregulate T-cell responses (117).

Arora and Kumaran (118) reported that, in addition to PTPN22, genes that encode complexes and proteins involved in the regulation of immunity, including $\mathrm{MHC}$, angiotensin-converting enzyme, cytotoxic $\mathrm{T}$ lymphocyte antigen-4, catechol-O-methyltransferase, estrogen receptor, mannan-binding lectin, HLA, NACHT leucine-rich repeat protein, X-box binding protein 1, FOXP1 and IL-2 receptor A, are involved in the immunopathogenesis of vitiligo. Alterations in the encoding genes, alongside other risk factors, cause melanocytes to be susceptible to apoptosis and induce the creation of melanocyte-reactive auto-antibodies and $\mathrm{T}$ cells (74). Furthermore, Arora and Kumaran (118) pointed out that HLA haplotypes, particularly HLA-A2, -DR4, -DR7 and -DQB1*0303, serve an important role in vitiligo predisposition. Additionally, our previous studies investigated variant genes for TNF- $\alpha$ (308G/A variant) (2) and PTPN22 (+1858 $\mathrm{C} / \mathrm{T}$ variant) (116).

Unbalanced expression of non-immune genes in vitiligo. In addition to genes involved in immunopathogenesis, numerous other genes may present altered expression once vitiligo lesions are clinically detectable. For instance, genes associated with the regulation of melanocyte development, function and survival have been identified (119-122). Furthermore, Strömberg et al (121) analyzed the gene expression profile of melanocytes in a cell culture isolated from a skin biopsy of a patient with vitiligo. The results identified the following five processes involved in the progression of vitiligo: i) development of melanocytes; ii) intracellular processing and trafficking of tyrosinase family proteins; iii) packaging and transport of melanosomes; iv) cell adhesion; and v) processing and presentation of antigens (121). In regard to genes associated with the depigmentation mechanism, Kingo et al $(119,120)$ reported lower expression levels of MITF and proopiomelanocortin (POMC) in vitiligo skin biopsies compared with healthy skin. Additionally, our previous study demonstrated that the upregulation of dopachrometautomerase (DCT), melanoma antigen recognized by Th1 cells (MLANA), calpain-3 (CAPN3) and tyrosinase-related protein 1 (TYRP1) expression was associated with depigmentation in patients with active vitiligo (123).

Downregulation of MITF and POMC expression is associated with lower skin pigmentation $(119,120)$. However, the mechanism by which the upregulation of DCT, TYRP1 and MLANA expression causes skin depigmentation in patients with vitiligo remains to be elucidated (123). Upregulation of these genes may be due to a compensatory mechanism in melanocytes; however, normal melanin production is not achieved. Another possibility is that the depigmentation of the skin is due to mutations in DCT, TYRP1 or MLANA, which may clarify why, despite being upregulated, depigmentation still occurs. Additionally, the association of vitiligo with CAPN3 overexpression is intriguing and should be further investigated, as the mechanism by which this enzyme affects skin pigmentation remains unknown.

Genes associated with apoptosis or homeostasis loss of melanocytes. The molecular mechanisms involved in the development of vitiligo have been investigated. Over the last decade, a genome-wide profiling approach was established to examine the expression levels of genes involved in the pathogenesis of vitiligo. Strömberg et al (121) identified 859 differentially expressed genes in the melanocytes of patients with vitiligo. These genes are mainly associated with melanocyte development, intracellular processing and transport of tyrosinase, packaging and transport of melanosomes, cell adhesion and antigen presentation. Furthermore, it has been hypothesized 
Table II. Downregulated genes associated with the loss of melanocyte homeostasis.

First author, year, or

Gene name

Protein

Function

(Refs.)

Regazzetti et al,2015 LEF1 Lymphoid enhancer-binding

Key transducer of the Wnt signaling

Segalés et al, 2016

Wei and Siegal, 2008

p38 MAPK P38 mitogen-activated protein kinase

PI3KCB Phosphatidylinositol-4,5-

bisphosphate 3-kinase

catalytic subunit $\beta$ isoform

Information

UniProtKB

UniProtKB

Bcl-2

B-cell lymphoma 2

National Center for

USF1

Upstream stimulatory factor 1

Biotechnology

Information factor-1

pathway and downstream effectors, including cadherin 2/3 and interferon regulatory factor 4 (IRF4).

The p38 MAPK signaling pathway serves roles in stress stimuli, including inflammatory cytokines, UV radiation, heat shock and osmotic shock. In addition, it is involved in cell differentiation, apoptosis and autophagy. Compared with normal physiological activity, increased and decreased activity has been associated with pathological events in several tissues, such as inflammation and altered muscle regeneration.

Encodes an isoform of the catalytic subunit of PI3K, which participates in the signaling pathways of eukaryotic cells. The encoded protein is the catalytic subunit for PI3K $\beta$, which serves a role in the neutrophil activation pathway. Additionally, these cells act in sites of injury and infection.

RPS6KB1 Ribosomal protein S6 kinase $\beta$-1 Promotes cell proliferation, growth and cell cycle progression, and the initiation of protein synthesis, a process mediated by cap-binding protein. Regulates protein synthesis and mediates cell survival by repressing the pro-apoptotic function of Bcl-2. The active form acts on several substrates in the pre-initiation complex. Additionally, it activates translation elongation.

Promotes cell survival, blocks dexamethasone-induced apoptosis and mediates the survival of post-mitotic Sertoli cells by suppressing the apoptotic activity of Bax, an apoptosis regulator. Isoforms $\alpha$ and $\sigma$ are expressed in various types of cancer cells, as prostate, breast and gastric cancer among others.

Binds to a symmetrical DNA sequence (E-box; 5'-CACGTG-3') and is expressed in various viral and cellular promoters. This gene encodes a cellular transcription factor that regulates various biological processes mediated by $\mathrm{p} 38$. USF1 disorders produce elevated levels of total serum cholesterol and/or triglycerides, or cause premature coronary heart disease. 


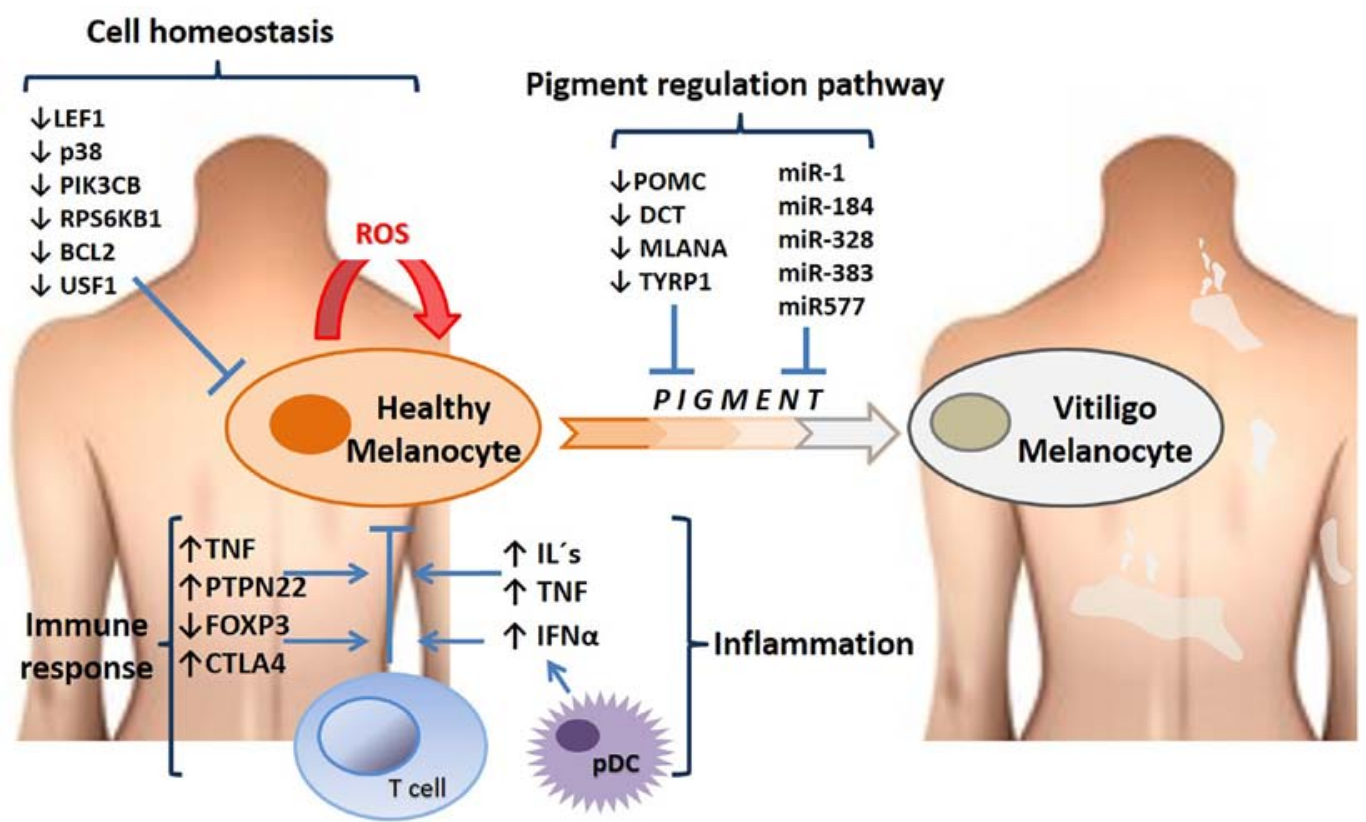

Figure 2. Altered gene expression profiles and signaling pathways in vitiligo. The figure highlights some of the genes and RNA levels that are upregulated or downregulated in patients with vitiligo, and some of the main processes in which these molecules participate, such as cell homoeostasis, the pigment pathway (genes that regulate pigmentation such as POMC, DCT and some microRNAs that regulate translation of genes in skin cells), immune response and inflammation. miR, microRNA; pDCs, plasmacytoid dendritic cells; ROS, reactive oxygen species; CTLA4, cytotoxic T-lymphocyte associated protein 4; FOXP3, forkhead box protein P3; LEF1, lymphoid enhancer-binding factor-1; PIK3CB, phosphatidylinositol-4,5-bisphosphate 3-kinase catalytic subunit $\beta$; PTPN22, protein tyrosine phosphatase non-receptor type 22; RPS6KB1, ribosomal protein S6 kinase $\beta$-1; USF1, upstream stimulatory factor 1; POMC, proopiomelanocortin; DCT, dopachrometautomerase; MLANA, melanoma antigen recognized by Th1 cells; TYRP1, tyrosinase-related protein 1.

that the development of autoimmunity against melanocytes may be a secondary event caused by the abnormal functioning of melanocytes in vitiligo (121). However, Shi et al (124) published a study in 2012 using an mRNA microarray from an avian model of human autoimmune vitiligo and demonstrated that the inflammatory/innate immune activity, oxidative stress and the adaptive immune response serve a predominant role in the loss of melanocytes, providing valuable information supporting the multifactorial etiology of vitiligo. Mansuri et al (125) identified microRNA (miRNA or $\mathrm{miR}$ ) signatures associated with vitiligo. miRNAs are small, non-coding RNA molecules that post-transcriptionally regulate gene expression by binding to target mRNAs, resulting in translational repression and gene silencing (125). miRNAs serve important roles in numerous aspects of homeostasis and disease. Patients with vitiligo presented with significantly increased expression levels of miR-1, miR-184, miR-383 and miR-577, while miR-328 expression was significantly downregulated in patients with vitiligo compared with controls (125). In silico analysis of these results indicated possible genetic targets affected by these miRNAs, including genes involved in inflammation (IL1B), immune response (PTPN22), oxidative stress (HSP60, HSP70) and skin pigmentation (TYRP1), and, therefore, demonstrated the crucial role of these molecules in the development of vitiligo (125).

In 2017, Dey-Rao et al (126) used in silico bioinformatics-based analyses to examine the vitiligo-blood transcriptome and identified several transcriptional 'hot spots', which were prioritized targets for identifying disease risk genes. Five molecules were identified: i) STAT1; ii) protein kinase C $\Delta$; iii) PTPN6; iv) MYC; and v) fibroblast growth factor receptor 2 (126), which all have the potential to be targeted by drugs for future therapies. Therefore, these and other molecular targets should be further explored due to their subtle contributions to vitiligo development, and may provide novel therapeutic targets.

Table II presents a group of downregulated genes associated with the loss of cell homeostasis in vitiligo (127-133), which were reported by Kingo et al $(119,120)$. The products of p38 and PIK3CB are protein kinases, which activate or deactivate proteins responding to stress and are implicated in cell apoptosis and differentiation (134). Therefore, a decrease in the expression levels of these genes can result in various detrimental effects on melanocyte differentiation, melanin production or the transportation of melanin granules to keratinocytes. The proteins encoded by RPS6KB1 (ribosomal) and Bcl-2 are apoptotic suppressors and their downregulation may explain melanocyte depletion in depigmented areas $(120,131,132)$. Fig. 2 presents the altered gene expression profiles and the affected pathways in vitiligo.

The gene descriptions in Table II suggest that p38, PIK3CB, upstream stimulatory factor 1 and lymphoid enhancer-binding factor-1 may exert pleiotropic effects. Therefore, it can be expected that alterations in the expression levels of these genes, whether combined or separately, may have several consequences for skin depigmentation as well as in other cells and organs.

\section{Conclusions}

Vitiligo is a multifactorial disease that can be activated by both external and internal factors. Among these, genetic and 
autoimmune factors are the principal factors for the initiation and progression of vitiligo lesions. Notably, melanocytes exhibit biological properties of immune cells and produce and release cytokines. Therefore, melanocytes can induce an autoimmune response in susceptible individuals. Vitiligo presents in several clinical forms and evolves in various ways, indicating that each of these forms have different etiologies and physiopathologies. Furthermore, a wide variety of genes have been reported to contribute to the risk of vitiligo. A number of these genes participate in key processes of melanocyte metabolism, skin homeostasis and apoptosis regulation, and encode mediators of the immune response. Vitiligo has a very complex pathogenesis and its treatment represents a challenge for dermatologists. The current review aimed to improve the understanding of the novel aspects of vitiligo pathogenesis and the molecular mechanisms involved in melanocyte destruction leading to hypopigmentation, allowing to identify future therapeutic targets to improve management efficacy and the quality of life of patients with vitiligo. However, further studies are required to further clarify the pathogenesis of vitiligo.

\section{Acknowledgements}

Not applicable.

\section{Funding}

No funding was received.

\section{Availability of data and materials}

Not applicable.

\section{Authors' contributions}

JOC, SLSF, CNSD, MASS, HGMR, DEKL, NAZS and OTVM performed the literature review, the data collection and drafted the manuscript. JOC, SLSF, CNSD, MASS, HGMR, DEKL, NAZS, OTVM, UW and TL improved and critically revised the manuscript. All authors read and approved the final manuscript.

\section{Ethics approval and consent to participate}

Not applicable.

\section{Patient consent for publication}

Not applicable.

\section{Competing interests}

The authors declare that they have no competing interests.

\section{References}

1. Le Poole IC, van den Wijngaard RM, Westerhof W, Dutrieux RP and Das PK: Presence or absence of melanocytes in vitiligo lesions: An immunohistochemical investigation. J Invest Dermatol 100: 816-822, 1993.
2. Salinas-Santander M, Díaz-García D, Rojas-Martínez A, Cantú-Salinas C, Sánchez-Domínguez C, Reyes-López M, Cerda-Flores RM, Ocampo-Candiani J and Ortiz-López R: Tumor necrosis factor- $\alpha-308 \mathrm{G} / \mathrm{A}$ polymorphism is associated with active vitiligo vulgaris in a northeastern Mexican population. Exp Ther Med 3: 893-897, 2012.

3. Le Poole IC, Das PK, van den Wijngaard RM, Bos JD and Westerhof W: Review of the etiopathomechanism of vitiligo: A convergence theory. Exp Dermatol 2: 145-153, 1993.

4. Rodrigues M, Ezzedine K, Hamzavi I, Pandya AG and Harris JE; Vitiligo Working Group: New discoveries in the pathogenesis and classification of vitiligo. J Am Acad Dermatol 77: 1-13, 2017.

5. Matin R: Vitiligo. BMJ Clin Evid 2008: 1717, 2008.

6. Costin GE and Hearing VJ: Human skin pigmentation: Melanocytes modulate skin color in response to stress. FASEB J 21: 976-994, 2007.

7. Hara M, Toyoda M, Yaar M, Bhawan J, Avila EM, Penner IR and Gilchrest BA: Innervation of melanocytes in human skin. J Exp Med 184: 1385-1395, 1996.

8. Reemann P, Reimann E, Ilmjärv S, Porosaar O, Silm H, Jaks V, Vasar E, Kingo K and Kõks S: Melanocytes in the skin-comparative whole transcriptome analysis of main skin cell types. PLoS One 9: e115717, 2014.

9. Slominski A, Zmijewski MA and Pawelek J: L-tyrosine and L-dihydroxyphenylalanine as hormone-like regulators of melanocyte functions. Pigment Cell Melanoma Res 25: 14-27, 2012.

10. Solano F: On the metal cofactor in the tyrosinase family. Int J Mol Sci 19: 633, 2018

11. Sturm RA, Teasdale RD and Box NF: Human pigmentation genes: Identification, structure and consequences of polymorphic variation. Gene 277: 49-62, 2001.

12. D'Mello SA, Finlay GJ, Baguley BC and Askarian-Amiri ME: Signaling pathways in melanogenesis. Int J Mol Sci 17: 1144, 2016.

13. Ortonne JP: Normal and abnormal skin color. Ann Dermatol Venereol 139 (Suppl 4): S125-S129, 2012.

14. Brenner $\mathrm{M}$ and Hearing VJ: The protective role of melanin against UV damage in human skin. Photochem Photobiol 84: 539-549, 2008.

15. Hong Y, Song B, Chen HD and Gao XH: Melanocytes and skin immunity. J Investig Dermatol Symp Proc 17: 37-39, 2015.

16. Elgendi A, Eslam A, Eman A, Nancy W, Karem K, Osama A and Ahmed E: Association of HLA Class I and II Antigens with Vitiligo in Egyptian Population. Molecular Enzymology and Drug Targets, 2016 Vol 02. DOI: 10.21767/2572-5475.10011.

17. Kirnbauer R, Charvat B, Schauer E, Köck A, Urbanski A Förster E, Neuner P, Assmann I, Luger TA and Schwarz T: Modulation of intercellular adhesion molecule-1 expression on human melanocytes and melanoma cells: Evidence for a regulatory role of IL-6, IL-7, TNF beta, and UVB light. J Invest Dermatol 98: 320-326, 1992.

18. Gasque P and Jaffar-Bandjee MC: The immunology and inflammatory responses of human melanocytes in infectious diseases. J Infect 71: 413-421, 2015.

19. Plonka PM, Passeron T, Brenner M, Tobin DJ, Shibahara S, Thomas A, Slominski A, Kadekaro AL, Hershkovitz D, Peters E, et al: What are melanocytes really doing all day long...? Exp Dermatol 18: 799-819, 2009.

20. Fisher GJ, Kang S, Varani J, Bata-Csorgo Z, Wan Y, Datta S and Voorhees JJ: Mechanisms of photoaging and chronological skin aging. Arch Dermatol 138: 1462-1470, 2002.

21. Kvam E and Tyrrell RM: Induction of oxidative DNA base damage in human skin cells by UV and near visible radiation. Carcinogenesis 18: 2379-2384, 1997.

22. Sander CS, Chang H, Hamm F, Elsner P and Thiele JJ: Role of oxidative stress and the antioxidant network in cutaneous carcinogenesis. Int J Dermatol 43: 326-335, 2004.

23. Tornaletti S and Pfeifer GP: UV damage and repair mechanisms in mammalian cells. Bioessays 18: 221-228, 1996.

24. Linge C: Relevance of in vitro melanocytic cell studies to the understanding of melanoma. Cancer Surv 26: 71-87, 1996.

25. Vink AA and Roza L: Biological consequences of cyclobutane pyrimidine dimers. J Photochem Photobiol B 65: 101-104, 2001.

26. Ezzedine K, Lim HW, Suzuki T, Katayama I, Hamzavi I, Lan CC, Goh BK, Anbar T, Silva de Castro C, Lee AY, et al: Revised classification/nomenclature of vitiligo and related issues: The vitiligo global issues consensus conference. Pigment Cell Melanoma Res 25: E1-E13, 2012. 
27. van Geel N, Speeckaert R, Taieb A, Picardo M, Böhm M, Gawkrodger DJ, Schallreuter K, Bennett DC, van der Veen W, Whitton M, et al: Koebner's phenomenon in vitiligo: European position paper. Pigment Cell Melanoma Res 24: 564-573, 2011.

28. Taïeb A and Picardo M: Clinical practice. Vitiligo. N Engl J Med 360: 160-169, 2009.

29. Moellmann G, Klein-Angerer S, Scollay DA, Nordlund JJ and Lerner AB: Extracellular granular material and degeneration of keratinocytes in the normally pigmented epidermis of patients with vitiligo. J Invest Dermatol 79: 321-330, 1982.

30. Falabella R, Arrunategui A, Barona MI and Alzate A: The minigrafting test for vitiligo: Detection of stable lesions for melanocyte transplantation. J Am Acad Dermatol 32 (2 Pt 1): 228-232, 1995

31. Krüger $\mathrm{C}$ and Schallreuter KU: A review of the worldwide prevalence of vitiligo in children/adolescents and adults. Int J Dermatol 51: 1206-1212, 2012.

32. Sehgal VN and Srivastava G: Vitiligo: Compendium of clinico-epidemiological features. Indian J Dermatol Venereol Leprol 73: 149-156, 2007.

33. Martis J, Bhat R, Nandakishore B and Shetty JN: A clinical study of vitiligo. Indian J Dermatol Venereol Leprol 68: 92-93, 2002.

34. Cesar Silva de Castro C and Miot HA: Prevalence of vitiligo in Brazil-A population survey. Pigment Cell Melanoma Res 31: 448-450, 2018

35. Zhang Y, Cai Y, Shi M, Jiang S, Cui S, Wu Y, Gao XH and Chen HD: The prevalence of vitiligo: A meta-analysis. PLoS One 11: e0163806, 2016.

36. Wang X, Du J, Wang T, Zhou C, Shen Y, Ding X, Tian S, Liu Y, Peng G, Xue S, et al: Prevalence and clinical profile of vitiligo in China: A community-based study in six cities. Acta Derm Venereol 93: 62-65, 2013.

37. Habib A and Raza N: Clinical pattern of vitiligo. J Coll Physicians Surg Pak 22: 61-62, 2012.

38. Salinas-Santander M, Sanchez-Dominguez C, Cantú-Salinas C, Ocampo-Garza J, Cerda-Flores R, Ortiz-López R and Ocampo-Candiani J: Vitiligo: Factores asociados con su aparición en pacientes del Noreste de México. Dermatol Rev Mex: 232-238, 2014 (In Spanish)

39. Yaghoobi R, Omidian M and Bagherani N: Vitiligo: A review of the published work. J Dermatol 38: 419-431, 2011

40. Huggins RH, Janusz CA and Schwartz RA: Vitiligo: A sign of systemic disease. Indian J Dermatol Venereol Leprol 72: 68-71, 2006.

41. Jin Y, Mailloux CM, Gowan K, Riccardi SL, LaBerge G, Bennett DC, Fain PR and Spritz RA: NALP1 in vitiligo-associated multiple autoimmune disease. N Engl J Med 356: 1216-1225, 2007.

42. Vázquez-Martínez OT, Velásquez-Arenas L, Méndez-Olvera $\mathrm{N}$ and Ocampo-Candiani J: Vitiligo. Overview and current therapeutics. Dermatología CMQ 4: 187-192, 2006.

43. Chen YT, Chen YJ, Hwang CY, Lin MW, Chen TJ, Chen CC, Chu SY, Lee DD, Chang YT and Liu HN: Comorbidity profiles in association with vitiligo: A nationwide population-based study in Taiwan. J Eur Acad Dermatol Venereol 29: 1362-1369, 2015.

44. Dahir AM and Thomsen SF: Comorbidities in vitiligo: Comprehensive review. Int J Dermatol 57: 1157-1164, 2018.

45. Bae JM, Lee JH, Yun JS, Han B and Han TY: Vitiligo and overt thyroid diseases: A nationwide population-based study in Korea. J Am Acad Dermatol 76: 871-878, 2017

46. Sedighe M and Gholamhossein G: Thyroid dysfunction and thyroid antibodies in Iranian patients with vitiligo. Indian J Dermatol 53: 9-11, 2008.

47. Gopal KV, Rao GR and Kumar YH: Increased prevalence of thyroid dysfunction and diabetes mellitus in Indian vitiligo patients: A case-control study. Indian Dermatol Online J 5: 456-460, 2014

48. El-Gayyar MA, Helmy ME, Amer ER, Elsaied MA and Gaballah MA: Antimelanocyte antibodies: A possible role in patients with vitiligo. Indian J Dermatol 65: 33-37, 2020.

49. Liu CW and Huang YC: Vitiligo and autoantibodies: A systematic review and meta-analysis. J Dtsch Dermatol Ges 16: 845-851, 2018.

50. Genetics Home Reference. Vitiligo. Inheritance Pattern. Available at: https://ghr.nlm.nih.gov/condition/vitiligo\#inheritance (last accessed 8 July 2019).

51. Alenizi DA: Consanguinity pattern and heritability of Vitiligo in Arar, Saudi Arabia. J Family Community Med 21: 13-16, 2014.
52. Allam $\mathrm{M}$ and Riad $\mathrm{H}$ : Concise review of recent studies in vitiligo. Qatar Med J 2013: 1-19, 2013.

53. Franks AL and Slansky JE: Multiple associations between a broad spectrum of autoimmune diseases, chronic inflammatory diseases and cancer. Anticancer Res 32: 1119-1136, 2012.

54. Asilian A, Momeni I and Khosravani P: Vitiligo associated with esophageal adenocarcinoma. Int J Prev Med 4: 489-490, 2013.

55. Balasubramanian A: Vitiligo associated with breast cancer-a report of two cases. Int J Cur Res Rev 7: 56-58, 2015.

56. Manga P, Elbuluk N and Orlow SJ: Recent advances in understanding vitiligo. F1000Res 5: F1000 Faculty Rev-2234, 2016

57. Patel S, Rauf A, Khan H, Meher BR and Hassan SSU: A holistic review on the autoimmune disease vitiligo with emphasis on the causal factors. Biomed Pharmacother 92: 501-508, 2017.

58. Giang J, Seelen MAJ, van Doorn MBA, Rissmann R, Prens EP and Damman J: Complement activation in inflammatory skin diseases. Front Immunol 9: 639, 2018

59. Ricklin D, Reis ES, Mastellos DC, Gros P and Lambris JD: Complement component C3-The 'Swiss Army Knife' of innate immunity and host defense. Immunol Rev 274: 33-58, 2016.

60. Sandoval-Cruz M, García-Carrasco M, Sánchez-Porras R, Mendoza-Pinto C, Jiménez-Hernández M, Munguía-Realpozo P and Ruiz-Argüelles A: Immunopathogenesis of vitiligo. Autoimmun Rev 10: 762-765, 2011.

61. Basak PY, Adiloglu AK, Ceyhan AM, Tas T and Akkaya VB: The role of helper and regulatory $\mathrm{T}$ cells in the pathogenesis of vitiligo. J Am Acad Dermatol 60: 256-260, 2009.

62. Kotobuki Y, Tanemura A, Yang L, Itoi S, Wataya-Kaneda M, Murota H, Fujimoto M, Serada S, Naka T and Katayama I: Dysregulation of melanocyte function by Th17-related cytokines: Significance of Th17 cell infiltration in autoimmune vitiligo vulgaris. Pigment Cell Melanoma Res 25: 219-230, 2012.

63. Bassiouny DA and Shaker O: Role of interleukin-17 in the pathogenesis of vitiligo. Clin Exp Dermatol 36: 292-297, 2011.

64. Wang CQF, Akalu YT, Suarez-Farinas M, Gonzalez J, Mitsui H, Lowes MA, Orlow SJ, Manga P and Krueger JG: IL-17 and TNF synergistically modulate cytokine expression while suppressing melanogenesis: Potential relevance to psoriasis. J Invest Dermatol 133: 2741-2752, 2013

65. Moretti S, Fabbri P, Baroni G, Berti S, Bani D, Berti E, Nassini R, Lotti T and Massi D: Keratinocyte dysfunction in vitiligo epidermis: Cytokine microenvironment and correlation to keratinocyte apoptosis. Histol Histopathol 24: 849-857, 2009.

66. Webb KC, Tung R, Winterfield LS, Gottlieb AB, Eby JM, Henning SW and Le Poole IC: Tumour necrosis factor- $\alpha$ inhibition can stabilize disease in progressive vitiligo. $\mathrm{Br}$ J Dermatol 173: 641-650, 2015

67. Alghamdi K and Khurrum H: Methotrexate for the treatment of generalized vitiligo. Saudi Pharm J 21: 423-424, 2013.

68. Sandra A, Pai S and Shenoi SD: Unstable vitiligo responding to methotrexate. Indian J Dermatol Venereol Leprol 64: 309, 1998.

69. Garza-Mayers AC and Kroshinsky D: Low-dose methotrexate for vitiligo. J Drugs Dermatol 16: 705-706, 2017.

70. Singh H, Kumaran MS, Bains A and Parsad D: A randomized comparative study of oral corticosteroid minipulse and low-dose oral methotrexate in the treatment of unstable vitiligo. Dermatology 231: 286-290, 2015.

71. Abdelmaksoud A, Dave DD, Lotti T and Vestita M: Topical methotrexate $1 \%$ gel for treatment of vitiligo: A case report and review of the literature. Dermatol Ther 32: e13013, 2019.

72. Haller $\mathrm{O}$ and Kochs G: Human MxA protein: An interferon-induced dynamin-like GTPase with broad antiviral activity. J Interferon Cytokine Res 31: 79-87, 2011

73. Boniface K, Seneschal J, Picardo M and Taïeb A: Vitiligo: Focus on clinical aspects, immunopathogenesis, and therapy. Clin Rev Allergy Immunol 54: 52-67, 2018.

74. Rezk AF, Kemp DM, El-Domyati M, El-Din WH, Lee JB, Uitto J, Igoucheva $\mathrm{O}$ and Alexeev V: Misbalanced CXCL12 and CCL5 chemotactic signals in vitiligo onset and progression. J Invest Dermatol 137: 1126-1134, 2017.

75. Harris JE: Cellular stress and innate inflammation in organ-specific autoimmunity: Lessons learned from vitiligo. Immunol Rev 269: 11-25, 2016.

76. Li S, Zhu G, Yang Y, Jian Z, Guo S, Dai W, Shi Q, Ge R, Ma J, Liu L, et al: Oxidative stress drives $\mathrm{CD}^{+} \mathrm{T}$-cell skin trafficking in patients with vitiligo through CXCL16 upregulation by activating the unfolded protein response in keratinocytes. J Allergy Clin Immunol 140: 177-189.e9, 2017. 
77. Wańkowicz-Kalińska A, van den Wijngaard RM, Tigges BJ, Westerhof W, Ogg GS, Cerundolo V, Storkus WJ and Das PK: Immunopolarization of $\mathrm{CD}^{+}$and $\mathrm{CD}^{+} \mathrm{T}$ cells to type-1-like is associated with melanocyte loss in human vitiligo. Lab Invest 83: 683-695, 2003.

78. Xie H, Zhou F, Liu L, Zhu , Li Q, Li C and Gao T: Vitiligo: How do oxidative stress-induced autoantigens trigger autoimmunity? J Dermatol Sci 81: 3-9, 2016.

79. Le Poole IC, Wañkowicz-Kaliñska A, van den Wijngaard RM, Nickoloff BJ and Das PK: Autoimmune aspects of depigmentation in vitiligo. J Investig Dermatol Symp Proc 9: 68-72, 2004.

80. Le Poole IC, van den Wijngaard RM, Westerhof W and Das PK Presence of $\mathrm{T}$ cells and macrophages in inflammatory vitiligo skin parallels melanocyte disappearance. Am J Pathol 148: 1219-1228, 1996.

81. Palermo B, Campanelli R, Garbelli S, Mantovani S, Lantelme E, Brazzelli V, Ardigó M, Borroni G, Martinetti M, Badulli $\mathrm{C}$, et al: Specific cytotoxic T lymphocyte responses against Melan-A/MART1, tyrosinase and gp100 in vitiligo by the use of major histocompatibility complex/peptide tetramers: The role of cellular immunity in the etiopathogenesis of vitiligo. J Invest Dermatol 117: 326-332, 2001.

82. Relke $\mathrm{N}$ and Gooderham M: The use of janus kinase inhibitors in vitiligo: A review of the literature. J Cutan Med Surg 23: 298-306, 2019.

83. Rashighi M, Agarwal P, Richmond JM, Harris TH, Dresser K, Su MW, Zhou Y, Deng A, Hunter CA, Luster AD and Harris JE: CXCL10 is critical for the progression and maintenance of depigmentation in a mouse model of vitiligo. Sci Transl Med 6 : 223ra23, 2014.

84. Ciechanowicz P, Rakowska A, Sikora M and Rudnicka L: JAK-inhibitors in dermatology: Current evidence and future applications. J Dermatolog Treat 30: 648-658, 2019.

85. Craiglow BG and King BA: Tofacitinib citrate for the treatment of vitiligo: A pathogenesis-directed therapy. JAMA Dermatol 151: 1110-1112, 2015.

86. Speeckaert R, Dugardin J, Lambert J, Lapeere H, Verhaeghe E, Speeckaert MM and van Geel N: Critical appraisal of the oxidative stress pathway in vitiligo: A systematic review and meta-analysis. J Eur Acad Dermatol Venereol 32: 1089-1098, 2018.

87. Laddha NC, Dwivedi M, Mansuri MS, Gani AR, Ansarullah M, Ramachandran AV, Dalai S and Begum R: Vitiligo: Interplay between oxidative stress and immune system. Exp Dermatol 22: 245-250, 2013.

88. Dell'Anna ML, Urbanelli S, Mastrofrancesco A, Camera E, Iacovelli P, Leone G, Manini P, D'Ischia M and Picardo M Alterations of mitochondria in peripheral blood mononuclear cells of vitiligo patients. Pigment Cell Res 16: 553-559, 2003.

89. Schallreuter KU, Salem MA, Holtz S and Panske A: Basic evidence for epidermal $\mathrm{H} 2 \mathrm{O} 2 / \mathrm{ONOO}(-)$-mediated oxidation/nitration in segmental vitiligo is supported by repigmentation of skin and eyelashes after reduction of epiderma $\mathrm{H} 2 \mathrm{O} 2$ with topical NB-UVB-activated pseudocatalase PC-KUS FASEB J 27: 3113-3122, 2013

90. Xu P, Xue YN, Ji HH, Tan C and Guo S: $\mathrm{H}_{2} \mathrm{O}_{2}$-induced oxidative stress disrupts mitochondrial functions and impairs migratory potential of human epidermal melanocytes. Exp Dermatol 29 : 733-741, 2020

91. Alshiyab DM, Al-Qarqaz FA, Muhaidat JM, Alkhader YS Al-Sheyab RF and Jafaar SI: Comparison of the efficacy of Tacrolimus $0.1 \%$ ointment and Tacrolimus $0.1 \%$ plus topical pseudocatalase/superoxide dismutase gel in children with limited vitiligo: A randomized controlled trial. J Dermatolog Treat 1-4, 2020 (Epub ahead of print).

92. Mathachan SR, Khurana A, Gautam RK, Kulhari A, Sharma L and Sardana K: Does oxidative stress correlate with disease activity and severity in vitiligo? An analytical study. J Cosmet Dermatol, 2020 (Epub ahead of print).

93. Spritz RA: The genetics of generalized vitiligo and associated autoimmune diseases. J Dermatol Sci 41: 3-10, 2006.

94. Zhang XJ, Chen JJ and Liu JB: The genetic concept of vitiligo. J Dermatol Sci 39: 137-146, 2005.

95. Genetics Home Reference. MITF gene. Available at: https://ghr nlm.nih.gov/gene/MITF. (last accessed 8 July 2019).

96. Genetics Home Reference. POMC gene. Available at: https://ghr. nlm.nih.gov/gene/POMC. (last accessed 8 July 2019).

97. UniProtKB. UniProtKB-P40126 (TYRP2 HUMAN). Available at: https://www.uniprot.org/uniprot/P40126. (last accessed 8 July 2019).
98. UniProtKB. UniProtKB-P17643 (TYRP1_HUMAN). Available at: https://www.uniprot.org/uniprot/P17643. (last accessed 8 July 2019)

99. UniProtKB. UniProtKB-Q16655 (MAR1_HUMSN). Available at: https://www.uniprot.org/uniprot/Q16655. (last accessed 8 July 2019)

100. Genetics Home Reference. CAPN3 gene. Available at: https://ghr. nlm.nih.gov/gene/CAPN3. (last accessed 8 July 2019).

101. Al-Shobaili HA: Update on the genetics characterization of vitiligo. Int J Health Sci (Qassim) 5: 167-179, 2011.

102. Le Poole IC, Sarangarajan R, Zhao Y, Stennett LS, Brown TL, Sheth P, Miki T and Boissy RE: 'VIT1', a novel gene associated with vitiligo. Pigment Cell Res 14: 475-484, 2001.

103. Genetics Home Reference. CAT gene. Available at: https://ghr. nlm.nih.gov/gene/CAT. (last accessed 8 July 2019).

104. Casp CB, She JX and McCormack WT: Genetic association of the catalase gene (CAT) with vitiligo susceptibility. Pigment Cell Res 15: 62-66, 2002

105. Mosaad YM, Sallam M, Elsaied MA, Fathy H, Fawzy Z, Elzehery R, Shaat RM and El-Gilany AH: Association of CAT 389 T/C and -89 T/A gene polymorphisms with vitiligo: Relation with oxidative stress. J Egypt Women Dermatol Soc 14: 121-127, 2017.

106. UniProtKB. UniProtKD-P24821 (TENA_HUMAN). Available at: https://www.uniprot.org/uniprot/P24821. (last accessed 8 July 2019).

107. Le Poole IC, van den Wijngaard RM, Westerhof W and Das PK: Tenascin is overexpressed in vitiligo lesional skin and inhibits melanocyte adhesion. Br J Dermatol 137: 171-178, 1997.

108. Murphy-Ullrich JE: The de-adhesive activity of matricellular proteins: Is intermediate cell adhesion an adaptive state? J Clin Invest 107: 785-790, 2001.

109. Esmat SM, Hadidi HHE, Hegazy RA, Gawdat HI, Tawdy AM, Fawzy MM, AbdelHalim DM, Sultan OS and Shaker OG: Increased tenascin C and DKK1 in vitiligo: Possible role of fibroblasts in acral and non-acral disease. Arch Dermatol Res 310: 425-430, 2018.

110. Schunter JA, Löffler D, Wiesner T, Kovacs P, Badenhoop K, Aust G, Tönjes A, Müller P, Baber R, Simon JC, et al: A novel FoxD3 variant is associated with vitiligo and elevated thyroid auto-antibodies. J Clin Endocrinol Metab 100: E1335-E1342, 2015.

111. National Center for Biothechnology Information. Genes and Expression. Gene. FOXD3 forkhead box D3 [Homo sapiens (human)]. Available at: https://www.ncbi.nlm.nih. gov/gene/27022?report=full_report $\% 202017 \% 20$ Caption:\%20 1588786844. (last accesed 8 July 2019).

112. Alghamdi KM, Khurrum H, Taieb A and Ezzedine K: Treatment of generalized vitiligo with anti-TNF- $\alpha$ Agents. J Drugs Dermatol 11: 534-539, 2012

113. Wilson AG, de Vries N, Pociot F, di Giovine FS, van der Putte LB and Duff GW: An allelic polymorphism within the human tumor necrosis factor alpha promoter region is strongly associated with HLA A1, B8, and DR3 alleles. J Exp Med 177: 557-560, 1993.

114. Wilson AG, Symons JA, McDowell TL, McDevitt HO and Duff GW: Effects of a polymorphism in the human tumor necrosis factor alpha promoter on transcriptional activation. Proc Natl Acad Sci USA 94: 3195-3199, 1997.

115. Mitra S, De Sarkar S, Pradhan A, Pati AK, Pradhan R, Mondal D, Sen S, Ghosh A, Chatterjee S and Chatterjee M: Levels of oxidative damage and proinflammatory cytokines are enhanced in patients with active vitiligo. Free Radic Res 51: 986-994, 2017.

116. Garcia-Melendez ME, Salinas-Santander M, Sanchez-Dominguez C, Gonzalez-Cardenas $\mathrm{H}$, Cerda-Flores RM, Ocampo-Candiani J and Ortiz-López R: Protein tyrosine phosphatase PTPN22 $+1858 \mathrm{C} / \mathrm{T}$ polymorphism is associated with active vitiligo. Exp Ther Med 8: 1433-1437, 2014.

117. Vang T, Miletic AV, Bottini N and Mustelin T: Protein tyrosine phosphatase PTPN22 in human autoimmunity. Autoimmunity 40: 453-461, 2007.

118. Arora A and Kumaran M: Pathogenesis of vitiligo: An update. Pigment Int 4: 65-77, 2017.

119. Kingo K, Aunin E, Karelson M, Philips MA, Ratsep R, Silm H, Vasar E, Soomets U and Koks S: Gene expression analysis of melanocortin system in vitiligo. J Dermatol Sci 48: 113-122, 2007. 
120. Kingo K, Aunin E, Karelson M, Ratsep R, Silm H, Vasar E and Koks S: Expressional changes in the intracellular melanogenesis pathways and their possible role in the pathogenesis of vitiligo. J Dermatol Sci 52: 39-46, 2008.

121. Strömberg S, Bjorklund MG, Asplund A, Rimini R, Lundeberg J, Nilsson P, Ponten F and Olsson MJ: Transcriptional profiling of melanocytes from patients with vitiligo vulgaris. Pigment Cell Melanoma Res 21: 162-171, 2008.

122. Salinas Santander MA: Análisis del perfil de expresión de pacientes con vitiligo. Universidad Autónoma de Nuevo Leon, Repositorio Académico Digital, p 143, 2012. http://eprints.uanl. $\mathrm{mx} / 3248 /$

123. Salinas-Santander M, Trevino V, De la Rosa-Moreno E, Verduzco-Garza B, Sánchez-Domínguez CN, Cantú-Salinas C, Ocampo-Garza J, Lagos-Rodríguez A, Ocampo-Candiani J and Ortiz-López R: CAPN3, DCT, MLANA and TYRP1 are overexpressed in skin of vitiligo vulgaris Mexican patients. Exp Ther Med 15: 2804-2811, 2018.

124. Shi F, Kong BW, Song JJ, Lee JY, Dienglewicz RL and Erf GF: Understanding mechanisms of vitiligo development in Smyth line of chickens by transcriptomic microarray analysis of evolving autoimmune lesions. BMC Immunol 13: 18, 2012.

125. Mansuri MS, Singh M and Begum R: MiRNA signatures and transcriptional regulation of their target genes in vitiligo. J Dermatol Sci 84: 50-58, 2016.

126. Dey-Rao R and Sinha AA: Vitiligo blood transcriptomics provides new insights into disease mechanisms and identifies potential novel therapeutic targets. BMC Genomics 18: 109, 2017.

127. Regazzetti C, Joly F, Marty C, Rivier M, Mehul B, Reiniche P, Mounier C, Rival Y,Piwnica D, Cavalié M, et al: Transcriptional analysis of vitiligo skin reveals the alteration of WNT pathway: A promising target for repigmenting vitiligo patients. J Invest Dermatol 135: 3105-3114, 2015.
128. Segalés J, Perdiguero E and Muñoz-Cánoves P: Regulation of muscle stem cell functions: A focus on the p38 MAPK signaling pathway. Front Cell Dev Biol 4: 91, 2016.

129. Wei S and Siegal GP: Mechanisms modulating inflammatory osteolysis: A review with insights into therapeutic targets. Pathol Res Pract 204: 695-706, 2008

130. National Center of Biotechnology Information. Genes and Expression. Gene. PIK3CB phosphatidylinositol-4,5-bisphosphate 3-kinase catalytic subunit beta [Homo sapiens (human)]. Available at: https://www.ncbi.nlm.nih.gov/gene?Db=gene \&Cm $\mathrm{d}=$ ShowDetailView\&TermToSearch $=5291$. (last accessed 8 July 2019).

131. UniProtKB. UniProtKB-P23443 (KS6B1_HUMAN). Available at: https://www.uniprot.org/uniprot/P23443. (last accessed 8 July 2019)

132. UniProtKB. UniProtKB-Q07812 (BAX HUMAN). Available at: https://www.uniprot.org/uniprot/Q07812. (last accessed 8 July 2019).

133. National Center of Biotechnology Information. Genes and Expression. Gene. USF1 upstream transcription factor 1 [Homo sapiens (human)] Available at: https://www.ncbi.nlm. nih.gov/gene $? \mathrm{Db}=$ gene $\& \mathrm{Cmd}=$ ShowDetailView\&TermToSe $\operatorname{arch}=7391$. (last accessed 8 July 2019).

134. Manning G, Whyte DB, Martinez R, Hunter $T$ and Sudarsanam S: The protein kinase complement of the human genome. Science 298: 1912-1934, 2002.

(i) () $\Theta$ This work is licensed under a Creative Commons Attribution-NonCommercial-NoDerivatives 4.0 International (CC BY-NC-ND 4.0) License. 